\title{
Antibiotic stewardship - it starts with you!
}

'The thoughtless person playing with penicillin treatment is morally responsible for the death of the man who succumbs to infection with the penicillin resistant organism.'

Sir Alexander Fleming, 1945

This edition of the SAJCC contains two publications on issues surrounding the effects of inappropriate use of antibiotics, but also the benefits of having an antibiotic stewardship programme in an intensive care unit (ICU).

The first paper by Bidaisee et al. ${ }^{[1]}$ describes the patterns of resistance seen in a tertiary hospital ICU where there is a distinct lack of any antimicrobial stewardship initiatives and rational prescribing of antibiotics. This study revealed a high level of resistance among the pathogens seen in hospital acquired infections and a high mortality, which may be attributable to a number of factors. Studies have shown that mortality is significantly higher in patients infected with resistant organisms when compared with more susceptible organisms of the same species. ${ }^{[2]}$ The reasons for this may be multiple, but factors include underlying comorbidities, inappropriate initial therapy, suboptimal dosing of antibiotics in critical illness and selection of resistance by inappropriate use of antibiotics. ${ }^{[3]}$

Antibiotic stewardship is a strategy to preserve the life-saving power of antibiotics. Unfortunately, we have reached the end of the 'golden age' of antibiotics where we are faced with pan-drug resistance and no new antibiotics on the horizon for the foreseeable future. ${ }^{[4]}$ Antibiotic stewardship is a multidisciplinary initiative aimed at optimal use of antibiotics focusing on timing, dose, duration and de-escalation of antimicrobial therapy. The programme involves role players from all disciplines, including clinical pharmacists, nursing, infection control, microbiology and the clinicians involved in the care of the patient. A recent study has shown a reduction in the incidence of infection and colonisation with antibiotic-resistant bacteria and Clostridium difficile infection. ${ }^{[5]}$ The systematic review and meta-analysis showed that antibiotic stewardship programmes (ABS) were more effective when implemented along with infection control measures, especially hand hygiene interventions, than when implemented on there own. This was the first evidence to promote the implementation of an antibiotic stewardship programme by stakeholders and policymakers to reduce the burden of infections from antibiotic-resistant bacteria.

The second publication by Rout and Brysiewicz ${ }^{[6]}$ in this edition of the SAJCC, describes the integral role that the ICU nurse practitioner plays as part of the antibiotic stewardship team. This qualitative research found the ICU nurse to be an essential $\operatorname{cog}$ in the wheel that ensures the success of an antibiotic stewardship programme. Undoubtedly, any antibiotic stewardship programme is reliant on multidisciplinary input to ensure its success. This was shown in a study looking at the role of a clinical pharmacist in driving antibiotic stewardship in a group of private hospitals across South Africa (SA). ${ }^{[7]}$

This study was particularly relevant to the South African setting where infectious diseases specialists are not available at every hospital. The results from this implementation study showed that antibiotic stewardship initiatives can be driven by any member of the team provided the programme is sustainable and is supported by policymakers and stakeholders.
Daily defined doses per 1000 patient days (DDDs/ 1000 pt days) is the metric used for most ABS programmes to track and benchmark institutions in terms of success or failure of an ABS. This is easy to monitor and can identify problem areas early. The introduction of a dedicated antibiotic prescription chart and antibiotic stewardship ward rounds can reduce antibiotic consumption and pharmacy cost, particularly in resource limited environments. ${ }^{[8]}$ However, the acid test should be whether resistance patterns change as a result of ABS, since the ultimate goal of any ABS programme is to preserve the lifesustaining power of antibiotics. The Empiric Coverage Index is a novel index proposed to evaluate the local impact of antibiotic resistance on empirical coverage. ${ }^{[9]}$

So, the burning question that needs an answer is: What are the barriers to implementation of an ABS programme in your institution? This question was the focus of an Australian study that revealed interesting results after in-depth interviews were conducted with both doctors and nurses. Firstly, clinical ownership of the patient's condition is perceived to be challenged by ABS processes. Traditional hierarchies and etiquette are in conflict with ABS processes. Nurses are perceived to lack the knowledge and training to fulfill their role in $\mathrm{ABS}$ processes. Lastly, ABS teams challenge interspeciality and interprofessional relationships and this undermines optimal use of antibiotics. ${ }^{[10]}$ Thus, the success of any ABS programme will require some behaviour change among clinicians to ensure its sustainability.

Finally, the issue of governance of antibiotic prescription has been spearheaded by the World Health Organization on a global level. In 2016, for only the fourth time in history, a health topic took centre-stage at a United Nations (UN) General Assembly high-level meeting, with a focused day-long meeting on antibiotic resistance. The involvement of the UN underlines the significance of this threat to public health and progress towards the 2030 Sustainable Development Goals. ${ }^{[1]}$ At the local government level in SA, the Department of Health has thrown its support behind a National Strategic Framework tackling antimicrobial resistance. This ministerial advisory committee, led by the Director General for Health, has recently published guidelines on the implementation of the antimicrobial strategy in SA, the so-called 'One Health Approach'. Apart from outlining the ABS processes, this document calls for an integrative effort from multiple disciplines, including government sectors and partners working locally, nationally, and globally to attain optimal health for people, animals, and the environment. ${ }^{[12]}$

With veterinary medicine and agriculture coming on board to support the fight against antibiotic resistance, it begs the question to healthcare workers: Why aren't you?

\section{Malcolm Miller}

Department of Anaesthesia and Perioperative Medicine, Division of Critical Care, Groote Schuur Hospital, University of Cape Town, South Africa

S Afr J Crit Care 2017;33(2):34-35. DOI:10.7196/ SAJCC.2017.v33i2.351

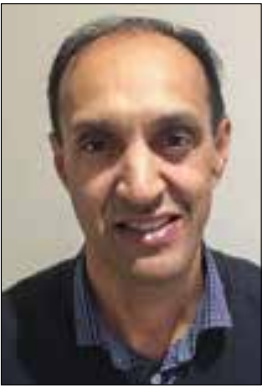


1. Bidaisee S, Harihara S, Chen D. Spectrum of microbial growth and antimicrobial usage in an intensive care unit of a tertiary care hospital in Trinidad, West Indies. S Afr J Crit Care 2017:33(2):39-44 https//doi.org/10.7196/SAJCC 2017.v33i2.284

2. Xu L, Sun X, Ma X. Systematic review and meta-analysis of mortality of patients infected with carbapenem-resistant Klebsiella pneumoniae. Ann Clin Microbiol Antimicrob 2017;16(1):18. https://doi.org/10.1186/s12941-017-0191-3

3. Barbier F, Lisboa T, Nseir S. Understanding why resistant bacteria are associated with higher mortality in ICU patients. Intensive Care Med 2016;42(12):2066-2069. https://doi.org/10.1007/ s00134-015-4138-x

4. Gould K. Antibiotics: From prehistory to the present day. J Antimicrob Chemother 2016;71(3):572575. https://doi.org/10.1093/jac/dkv484

5. Rout J, Brysiewicz P. Exploring the role of the ICU nurse in the antimicrobial stewardship team at a private hospital in KwaZulu-Natal, South Africa. S Afr J Crit Care 2017;33(2):46-50. https//doi. org/10.7196/SAJCC.2017.v33i2.331

6. Baur D, Gladstone BP, Burkert F, et al. Effect of antibiotic stewardship on the incidence of infection and colonisation with antibiotic-resistant bacteria and Clostridium difficile infection: A systematic review and meta-analysis. Lancet Infect Dis 2017;17(9):990-1001. https://doi. org/10.1016/s1473-3099(17)30325-0
7. Brink AJ, Messina AP, Feldman C, et al. Antimicrobial stewardship across 47 South African hospitals: An implementation study. Lancet Infect Dis 2016:16(9):1017-1025. https:/dol. org/10.1016/s1473-3099(16)30012-3

8. Boyles TH, Whitelaw A, Bamford C, et al. Antibiotic stewardship ward rounds and a dedicated prescription chart reduce antibiotic consumption and pharmacy costs without affecting inpatien mortality or re-admission rates. PLoS One 2013;8(12):e79747. https://doi.org/10.1371/journal. pone. 0079747

9. Hughes IS, Hurford A, Finley RL, Patrick DM, Wu J, Morris AM. How to measure the impacts of antibiotic resistance and antibiotic development on empiric therapy: New composite indices. BMJ 2016;6(12):e012040. https://doi.org/10.1136/bmjopen-2016-012040

10. Broom J, Broom A, Kirby E, Gibson AF, Post JJ. How do hospital respiratory clinicians perceive antimicrobial stewardship (AMS)? A qualitative study highlighting barriers to AMS in respiratory medicine. J Hosp Infect 2017;96(4):316-322. https://doi.org/10.1016/j.jhin.2017.05.001

11. Jasovsky D, Littmann J, Zorzet A, Cars O. Antimicrobial resistance - a threat to the world's sustainable development. Ups J Med Sci 2016;121(3):159-164. https://doi.org/10.1016/.j.jhin.2017.05.001

12. National Department of Health. Guidelines on implementation of the antimicrobial strategy in South Africa: One Health approach and governance. Pretoria: NDoH, 2017.

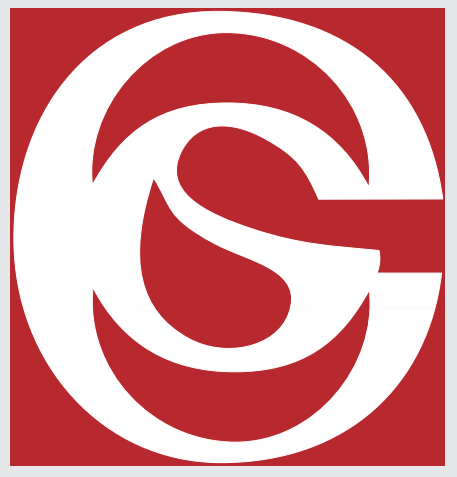

\section{CRITICAL CARE SOCIETY OF SOUTHERN AFRICA}

he Critical Care Society of Southern Africa (CCSSA) is a not-for-profit organisation
dedicated to improving the care of patients with life-threatening illness or injury. It does so through supporting its members in research and educational initiatives and related interventions.

Its members include doctors, nurses and allied healthcare professionals, e.g. physiotherapists, dieticians and technologists, who work in the field of Critical Care Medicine.

\section{Dedicated to quality care for the critically ill.}

\section{Alison Shaw - Royal House \\ CCSSA secretariat}

Mobile: +27 (0)82 5538201

Fax: +27 (0)86 6179423

Email: secretariat@criticalcare.org.za

www.criticalcare.org.za 